\title{
Prevalence of anemia in pregnant women and its impact on SNCU outcome
}

\author{
Seetharama Raju K ${ }^{1}$, Santhi Kothapalli², Gowri Shankar B. ${ }^{3}$ \\ ${ }^{1}$ Dr. Seetharama Raju K, Medical Superintendent, District Hospital, Vizianagaram. ${ }^{2}$ Dr. Santhi Kothapalli, Pediatrician, \\ SNCU, District Hospital, Vizianagaram. ${ }^{3}$ Dr. Gowri Shankar B, Civil Surgeon, Pediatrician, District Hospital, \\ Vizianagaram, Andhra Pradesh, India.
}

Corresponding Author: Dr. Santhi Kothapalli, Pediatrician, SNCU, District Hospital, Vizianagaram, Andhra Pradesh. Email: sanbenj@gmail.com

\begin{abstract}
Introduction: For India to reach sustainable development goal neonatal mortality should be decreased by half in the next 12 years. The present study was aimed to observe the prevalence of anemia in the mothers whose babies are admitted in our SNCU and its impact on neonatal mortality. Aims: 1. To study the prevalence and severity of anemia among mothers of babies who are admitted in Special New Born Care Unit (SNCU), district hospital, Vizianagaram. 2. To study the effect of maternal anemia on outcome of babies admitted into SNCU. Methods: It is a retrospective analytical study, conducted in the department of SNCU, District hospital, Vizianagaram, Andhra Pradesh, India. The 3-year data regarding mother's hemoglobin concentration and neonatal outcome in the form of discharges, referrals and deaths was analysed irrespective of the reason for admission and the diagnosis. The data was collected from April 2016 to March 2019 retrospectively from the SNCU records. This study was done to assess the prevalence of anemia; a preventable cause of neonatal morbidity and mortality and its impact on outcome of neonates admitted into our SNCU irrespective of the reason for admission and the diagnosis. Results: A total number of 7627 babies were admitted in SNCU, with various conditions in the above mentioned $3 y \mathrm{yr}$ period. Out of which hemoglobin value was available for 6558 mothers. The hemoglobin data of these 6558 mothers and the outcome of their babies irrespective of their diagnosis and the reason for admission was analysed. Anemia was found in 5076(95\%) mothers. Severe anemia (Hb: 4-6.9gm\%) was found in $27(0.4 \%)$ mothers and it was significantly associated with increased referrals and neonatal deaths. whereas mild and moderate anemia didn't have much impact on the SNCU outcome. Conclusion: Severe maternal anemia is a significant, independent and preventable risk factor for neonatal mortality.
\end{abstract}

Key words: Maternal anemia, Neonatal deaths, SNCU outcome

\section{Introduction}

In 2015, all the countries in the world started working towards new targets for the year 2030, the Sustainable Development Goals (SDGs). The proposed SDG target for child mortality aims to end all the preventable deaths of newborns and children under 5 years of age and to reduce neonatal mortality to at least as low as 12 deaths per 1,000 live births in all countries by 2030 . According to UNICEF report, India is currently not on track to meet the Sustainable Development Goal target for neonatal mortality of 12 by 2030. To achieve this goal, the country will have to reduce its neonatal deaths by half in the next 12 years. Neonatal

Manuscript received: $8^{\text {th }}$ August 2019

Reviewed: $18^{\text {th }}$ August 2019

Author Corrected: $26^{\text {th }}$ August 2019

Accepted for Publication: $31^{\text {st }}$ August 2019 period is the first 28 days of life, which is the most vulnerable period and carries the highest risk of mortality than any other period during childhood. According to a nationally representative mortality survey done by Dr. Diego G Bassani and Prof Prabhat Jha, three causes accounted for $78 \%$ of all neonatal deaths in India are prematurity \& low birthweight, neonatal infections and birth asphyxia \& birth trauma [1]. Lone FW et $a l,{ }^{2}$ in their study found that anemia during pregnancy is one of the most important risk factors which affect the birth weight and maturity.

Stangret A et al [3] described that decreased haemoglobin level causes changes in placental angiogenesis, which will decrease the availability of 


\section{Original Research Article}

oxygen to the growing fetus and causes restriction of foetal growth and causes low birth weight. Anaemia results in low birth weight babies and prematurity by inducing maternal and fetal stress, which stimulates the synthesis of corticotropin-releasing hormone (CRH). Elevated CRH concentration is a major risk factor for preterm labor, pregnancy-induced hypertension, eclampsia, and premature rupture of the membranes. $\mathrm{CRH}$ also increases fetal cortisol production, which in turn inhibit the foetal growth. Pregnant women with iron deficiency anemia are at increased risk of infection, which can be a predisposing foctor for preterm labour.

According to WHO global data base on anaemia, [4] prevalence of anemia in pregnant women is substantially high in developing countries. According to Balarajan $\mathrm{Y}$ et al [5] pregnant women are more at risk for anaemia due to increased demands during this period and physiological vulnerability especially in low-income and middle-income countries.

A systemic analysis done by Stevens GA et al [6] showed that maternal anaemia is an important global health problem that affects about 500 million women of reproductive age. McLean E et al in their study found that the most common causes for anaemia in pregnant women in middle- and low-income countries are dietary iron deficiency, hemoglobinopathies, macronutrient deficiencies, and infections such as malaria, HIV, and hookworm infestation etc. There are so many programmes initiated by government to control anemia; eg National nutritional anemia control programme under Ministry of Health \& Family Welfare Government of India. This programme focuses on regular consumption of iron rich food, provision of iron and folic acid supplements to high risk groups like pregnant and lactating women and preschool children and identification and treatment of severely anaemic cases.

Despite of all the anemia control measures, anemia has remained the major health problem across all the age groups, especially in female population.Treating anemia during pregnancy is more cost effective than treating its impact on new born babies. VIzianagaram district is an aspirational district with regard to neonatal mortality rate. In order to decrease the neonatal mortality rate in our SNCU, the prevalence and impact of maternal anaemia which is one of the preventable causes of neonatal mortality was to be studied.

Assessment of the prevalence of anaemia and its severity (according to WHO classification) in the mothers of newborn babies admitted in SNCU, district hospital, Vizianagaram was also done. The grade of anaemia which has direct and significant impact on SNCU outcome in the form of neonatal mortality was looked into.

\section{Materials and Methods}

The study design and setting: This is a retrospective analytical study, conducted in SNCU at the district hospital, Vizianagaram, which serves as a referral centre for the whole Vizianagaram district which includes a large tribal belt. The district hospital MCH block is a referral centre for all high-risk deliveries and sick newborn babies. A retrospective analysis of all newborn babies admitted in the SNCU over a 3-year period between April 2016 and March 2019 was undertaken. The mother's latest hemoglobin during pregnancy and the outcome of the newborn were recorded and analyzed. The mother infant dyad was excluded from analysis if the mother's hemoglobin result was not available. The hemoglobin level was estimated by cyanmethemoglobin method and anemia during pregnancy was classified as per the WHO classification as shown in Table 1.

Table-1: WHO classification of anemia during pregnancy.

\begin{tabular}{|c|c|}
\hline Normal hemoglobin & $\geq 11 \mathrm{gm} / \mathrm{dl}$ \\
\hline Mild anemia & $9-10.9 \mathrm{gm} / \mathrm{dl}$ \\
\hline Moderate anemia & $7-8.9 \mathrm{gm} / \mathrm{dl}$ \\
\hline Severe anemia & $4-6.9 \mathrm{gm} / \mathrm{dl}$ \\
\hline Very severe anemia & $<4 \mathrm{gm} / \mathrm{dl}$ \\
\hline
\end{tabular}

Prevalence and severity of anemia among the mothers of new born babies admitted in SNCU was calculated. The effect of the presence and the degree of maternal anemia on neonatal outcome was analyzed. Outcome was classified as successful discharges, referrals, left against medical advice (LAMAs) and deaths. Our referral criteria to a higher centre is mentioned below. 


\section{SNCU Vizianagaram Referral criteria:}

1. Babies with shock not responding to fluid challenge and vasopressors.

Babies with suspected congenital heart disease either cyanotic or acyanotic; who needs further evaluation at higher centre by a cardiologist

2. Babies born with major congenital malformations requiring surgery e.g. Tracheo- esophageal fistula, diaphragmatic hernia, meningomyelocele etc.

3. Babies with refractory seizures; not controlled even with midazolam infusion.

4. Neonates with bleeding disorders who require blood component therapy.

Statistical analysis: The data was taken into SSPS version20.0 software package and statistical analysis was done. Chi square test was applied to test the significance of association.

\section{Results}

7627 newborn babies were admitted in the SNCU during the study period, of which 1623 (24.7\%) are out born. 1096 were excluded as the mother's hemoglobin was not available and 6558 mother infant dyads were included in the study. $6240(95 \%)$ of the mothers are found to be anaemic. Mild anemia was found in $77.4 \%$, moderate anemia was found in $17.3 \%$ and severe anemia was found in $0.4 \%$ of the mothers. None of the mothers in the study group has very severe anemia. The severity and grading of anemia is shown in Figure 1.

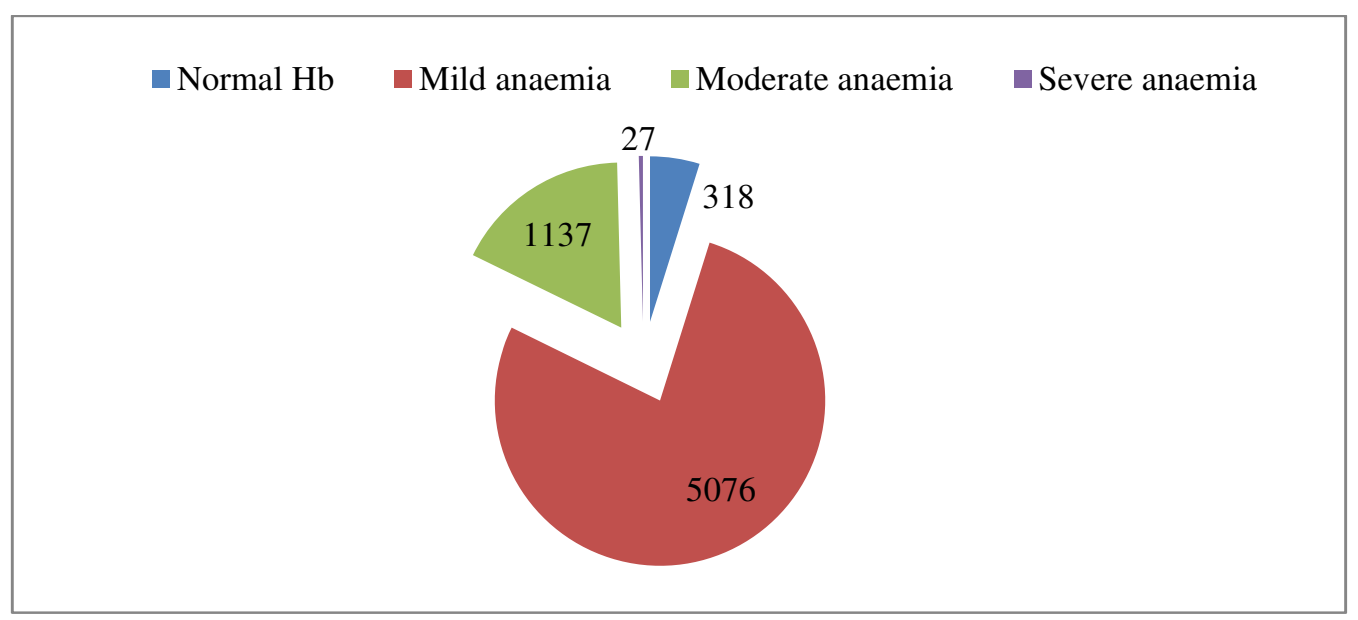

Figure 1: Severity and grading of maternal anaemia

The morbidity profile of newborns admitted in the SNCU is shown in Table 2. An admitted newborn may have more than one diagnosis and the most important diagnosis is mentioned here. 'Others' include hypoglycaemia, environmental hyperthermia, multiple pustules etc.

Table-2: Morbidity profile of SNCU admissions.

\begin{tabular}{|c|c|}
\hline Morbidity Profile & Percentage \\
\hline Neonatal Jaundice & $(1836) 28 \%$ \\
\hline Preterm/Low Birth Weight/RDS & $(1534) 23.4 \%$ \\
\hline Sepsis & $(1128) 17.2 \%$ \\
\hline Birth Asphyxia/HIE related & $(984) 15 \%$ \\
\hline TTNB & $(512) 7.8 \%$ \\
\hline Congenital Malformation & $(98) 1.5 \%$ \\
\hline Others & $(465) 7.1 \%$ \\
\hline
\end{tabular}


Original Research Article

Table-3: Comparison of severity of anemia and outcome of newborns admitted in SNCU

\begin{tabular}{|l|c|c|c|c|}
\hline & Discharged & Expired & LAMA & Referred \\
\hline Normal Hb & $279(87.70 \%)$ & $9(2.80 \%)$ & $13(4.10 \%)$ & $17(5.30 \%)$ \\
\hline Mild anemia & $4574(90.10 \%)$ & $114(2.20 \%)$ & $103(2 \%)$ & $285(5.60 \%)$ \\
\hline Moderate anemia & $994(87.40 \%)$ & $28(2.50 \%)$ & $25(2.20 \%)$ & $90(7.90 \%)$ \\
\hline & 19 & 4 & 0 & 4 \\
Severe anemia & $(70.40 \%)$ & $(14.80 \%)$ & $(0 \%)$ & $(14.80 \%)$ \\
\hline
\end{tabular}

$\mathrm{p}-0.0001$

Severe maternal anemia was significantly associated with increased referrals $(14.8 \%)$ from the SNCU to a higher centre and neonatal deaths (14.8\%). Among the mothers with normal hemoglobin and lesser grades of anemia the neonatal deaths and referral to higher centre were similar (Fig: 2). Neonatal mortality was $2.2 \%$ to $2.8 \%$ among babies born to mothers with normal \& moderate anemia whereas it was $14.8 \%$ for babies born to mothers with severe anemia. Majority of babies $(87.7 \%)$ who were born to mothers with normal hemoglobin and lesser degrees of anemia were successfully discharged as compared to $70.4 \%$ of babies who were born to mothers with very severe anemia which is statistically significant. Percentage of SNCU referrals is almost 2-3 times more severe maternal anemia as compared to normal and Percentage of referrals of babies who are admitted in SNCU increased with increasing severity of maternal anemia lesser degrees of maternal anemia. Babies who left against medical advice were nil among babies born to mothers with severe anemia as they were extremely sick at the time of admission.

\section{Discussion}

Dr. Diego G Bassani and Prof Prabhat Jha in their study mentioned that the most important three causes accounting for $78 \%$ of all neonatal deaths in India are prematurity \& low birth-weight, neonatal infections and birth asphyxia which constitutes a substantial portion of neonatal mortality'. Anemia during pregnancy is one of the most important risk factors which affect the pregnancy outcome and is responsible for increased incidence of low birth weight, premature births and increased perinatal mortality. A cohort study done by Lone FW et al ${ }^{2}$ in 629 pregnant women from October 2001 to October 2002, 313 were anaemic (hemoglobin $<11 \mathrm{~g} / \mathrm{dl}$ in labour and on two previous occasions in current pregnancy).

A total of 316 women had hemoglobin $>11 \mathrm{~g} / \mathrm{dl}$ at all times in pregnancy and were labelled as non-anaemic. Perinatal outcomes included preterm delivery, low birth weight (LBW) at delivery, intrauterine growth restriction, perinatal mortality, APGAR score at 1 and 5 min, intrauterine foetal demise (IUD) were significantly associated with low maternal hemoglobin levels. In the same study they have found that there was a 3.7 times greater risk of intrauterine foetal death among the anaemic women than the non-anaemic women.

According to WHO global data base on anemia 1993 to 2005 , anemia was prevalent in $40.8 \%$ of pregnant women). Bora $\mathrm{R}$ et al [8] conducted a study in North east india, to determine the prevalence of anemia in pregnant women and the association between maternal hemoglobin $(\mathrm{Hb})$ at delivery and neonatal outcomes were determined. Anemia was found in $89.6 \%$ mothers and $8.3 \%$ of them had severe anemia. In a hospitalbased study in Jharkhand done by Manju Merina Bara et al [9], the overall prevalence of anemia was $76 \%$ with mild anemia in $20 \%$, moderate anemia in $44 \%$, severe anemia in $31 \%$ and very severe anemia in $4 \%$ of pregnant ladies. In a study done in RHTC \& CAIMS Hospital karimnagar, Telangana, India by Rajmouli et al [10] prevalence of moderate and severe anemia during pregnancy was reported to be $36.8 \%$ and $6.9 \%$ respectively.

In the present study, prevalence of anemia was noted to be $95 \%$ which is very high compared to the above studies in India. This could be because the present study was conducted among mother baby dyads where the babies required SNCU admission. Inspite of very high prevalence of anemia, prevalence of moderate and severe anemia was relatively low $17 \%$ and $0.4 \%$ respectively and none of them had very severe anemia. The relatively lower prevalence of moderate and severe anemia in the present study group could be because of the various government initiatives on $\mathrm{MCH}$ services in our district. Also, most of these mothers had antenatal cards and were being followed up regularly in their respective government health centres. The prevalence 


\section{Original Research Article}

and severity of anemia may be even more among pregnant women who do not have regular antenatal follow ups. Some of the pregnant ladies may still be delivering at home because of various reasons despite many initiatives by government to encourage deliveries at the health centres.

Prevalence and severity of anemia may be high in such groups. Among tribal communities, added risk of hemoglobinopathies in addition to nutritional deficiency may contribute to anemia. In a study done by Haritha $\mathrm{P}$ et al [11] revealed prevalence of hemoglobinopathies among the Konda Kammaras of Visakhapatnam District, Andhra Pradesh was found to be $14.56 \%$. Konda Kammaras are a Scheduled Tribe, who also live in the adjoining scheduled areas like Vizianagaram, Srikakulam etc.

According to Jagadish Kumar et al [12], maternal anemia in the last trimester was associated with increased incidence of prematurity and low birth weight babies which indicates that maternal anemia in the last trimester has more effect on foetus than maternal anemia during early pregnancy. At SNCU, Vizianagaram, the association between maternal hemoglobin level before delivery and its association with neonatal outcome have been studied.

The present study also showed that severe anemia in the last trimester has adversely affected the neonatal outcome in the form of referrals and deaths. In the present study, only severe anemia during pregnancy was associated with increased neonatal deaths and referrals, whereas mild and moderate anemia did not adversely affect the neonatal outcome. A similar prospective analysis from pregnancy registry done by Park Stifanie et al [13] on approximately 92000 to 93000 mother infant dyad in rural India and Pakistan showed only severe anemia during pregnancy has affected neonatal outcome and not the mild and moderate anemia. In this study, $87.8 \%$ of the newborns were born to mothers who were anaemic (mild 37.9\%, moderate $49.1 \%$, and severe $0.7 \%$ ).

Fetal and neonatal mortality was associated with severe anemia. They have studied stillbirth rate which was significantly associated with severe anemia, as compared with babies born to mild and moderate anemia. They also have assessed 28-day neonatal mortality which again was significantly high in babies born to mothers with severe anemia as compared to babies born to mothers with mild and moderate anemia. In this study, mothers with severe anemia were less than
$1 \%$ which is similar to the present study. However, percentage of mothers with moderate anemia are almost two and half times more than the present study. Since percentage of mothers with severe anemia was similar to that of the present study, similar results were obtained in terms of neonatal deaths.

There were many studies which looked at the effect of anemia during pregnancy on maternal deaths, low birth weight, prematurity and still births. In a follow up study done by Grace Stephen et al [14], in Northern Tanzania on 539 pregnant women, the prevalence of anemia among pregnant mothers was found to be only $18 \%$ and $2 \%$ of them had severe anemia. At delivery, there were 10 stillbirths, 16 low birth weight (LBW) newborns, and 2 preterm birth cases. In this study, there was no association between anemia and LBW, preterm birth or stillbirths. However, they have not studied the effect of various grades of anemia (severe anemia) on birth weight, maturity, still births and neonatal deaths.

A population based prospective cohort study done in China by Y. Zhang et al [15], maternal anemia was not associated with increased risk of neonatal mortality; however, they have not analysed its correlation with severity of anemia. This group of mothers may not have severe anemia. In this study, maternal anemia was not associated with increased risk of mortality in the neonatal period. In fact, women with anemia (hemoglobin of $9 \mathrm{gm} \%$ ) during the third trimester had protective effect and there was reduction of stillbirths.

Meta-analysis done by Rahman MM et al [16], in lowand middle-income countries showed that there were significantly higher risks of low birth weight, pre-term birth, peri-natal mortality, and neonatal mortality in pregnant women with anemia. South Asian, African, and low-income countries had a higher prevalence of anemia than did other Asian and upper-middle-income countries. Overall, in low and middle-income countries, $12 \%$ of low birth weight, $19 \%$ of preterm births, and $18 \%$ of peri-natal mortality were attributable to maternal anemia.

However, they have not graded maternal anemia according to severity. In the present study, $14 \%$ of the babies born to mothers with severe anemia died and $14 \%$ of the babies born to mothers with severe anemia got referred because of severity of illness. They have not studied the effect of severity of anemia and effect of different grades of anemia on outcome of newborn babies related to NICU admissions. A retrospective study, conducted in Vardhman Mahavir medical college 


\section{Original Research Article}

and Safdarjang hospital, New Delhi by Kumari Usha Rani et al [17] also showed that there is increased risk of preterm delivery, low birth weight, poor APGAR score and admission of baby in neonatal intensive care unit was more in anaemic group and it increased with severity of anemia which was statistically significant. The increase in risk of early neonatal death was not significant in mild/moderate anaemic group ( $\mathrm{P}$ value $0.326)$ while it was statistically significant in severely anaemic group ( $\mathrm{P}$ value 0.004) [18]. These findings are similar to the present study where severe anemia alone was associated with increased neonatal mortality. Strengths of the study are large sample size and accurate data entry software. Limitation of the present study was that it included mother and baby dyad who utilised government facility only.

\section{Conclusion}

There is a high prevalence of anemia in Vizianagaram district among mothers of newborns who get admitted in the SNCU, though prevelance of severe anemia is relatively low. Irrespective of cause and diagnosis of new born admissions, severe anemia during pregnancy had shown significant association with negative outcomes in the form of increased referrals and deaths. Severe maternal anemia can be considered as significant and independent risk factor for neonatal mortality. The continued and intensified anemia control programme during pregnancy can help decrease neonatal mortality rate. It is highly recommended to plan for screening of hemoglobinopathies in the tribal area in Vizianagaram district along with nutritional anemia control measures.

\section{What this study adds to the existing knowledge?}

Despite of numerous nutritional anaemia control programmes and well-structured antenatal care at government health facilities in Vizianagaram district, severe anaemia is persisting, and it has significant impact on neonatal mortality. Apart from intensifying nutritional anaemia control measures in Vizianagaram district, non-nutritional factors contributing to severe maternal anaemia like hemoglobinopathies, infections such as chronic malaria and HIV should be screened and managed even from adolescent age group to decrease neonatal mortality rate in this district.

\section{Author contributions}

- Dr. Santhi Kothapalli: Planned, co-ordinated, designed, interpreted the data and drafted the manuscript.
- Dr.Seetharama Raju K: Collected, compiled, analysed the data and revised the manuscript.

- Dr. Gowri Shankar B: Helped in collecting data and revising the draft.

Funding: Nil, Conflict of interest: None initiated, Permission from IRB: Yes

Acknowledgment: Dr. Winsley Rose MD, MSc (Epi) Professor, Department of Pediatrics and Pediatric Infectious Diseases, Christian Medical College Professor Paediatrics, $\mathrm{CMCH}$, Vellore for reviewing the draft and providing expert comments. Dr. Anil Benjamin, Medical Superintendent, Shalom Medical Centre, Gotlam for critical review and technical editing of the manuscript.

\section{References}

1. Bassani DG, Jha P. Causes of neonatal and child mortality in India: a nationally representative mortality survey.Lancet. 2010;376(9755):1853-1860.doi: 10.1016 / S0140-6736 (10)61461-4.

2. Lone FW, Qureshi RN, Emanuel F. Maternal anemia and its impact on peri-natal outcome.Trop Med Int Health. 2004; 9(4):486-90. doi:10.1111/j. 1365-3156. 2004. 01222.x

3. Stangret A, Wnuk A, Szewczyk G, Pyzlak M, Szukiewicz D. Maternal hemoglobin concentration and hematocrit values may affect fetus development by influencing placental angiogenesis. J. Matern. Fetal Neonatal Med. 2017;30(2):199-204. doi: 10.3109/ 1476 7058. 2016.1168395.

4. World Health Organization. Worldwide prevalence of anemia 1993-2005: WHO global data base on anaemia. http://whqlibdoc.who.int/publications/ 2008/ 9789241596657_eng.pdf.

5. Balarajan Y, Ramakrishnan U, Ozaltin E, Shankar $\mathrm{AH}$, Subramanian SV. Anaemia in low-income and middle-income countries. Lancet. 2011;378(9809): 2123-2135. doi: 10.1016/S0140-6736(10)62304-5

6. Stevens GA, Finucane MM, De-Regil LM, Paciorek CJ, Flaxman SR, Branca F. Global, regional, and national trends in haemoglobin concentration and prevalence of total and severe anaemia in children and pregnant and non-pregnant women from 1995-2011: a systematic analysis of population-representative data. Lancet Glob Health. 2013;1(1):e16-e25. doi: 10.1016/ S2214-109X (13)70001-9. Epub 2013 Jun 25. 


\section{Original Research Article}

7. McLean E, Cogswell M, Egli I, Wojdyla D, de Benoist B. Worldwide prevalence of anaemia, WHO vitamin and mineral nutrition information system, 1993-2005. Public Health Nutr. 2009;12(4):444-454. doi: 10.1017/S1368980008002401. Epub 2008 May 23.

8. Bora R, Sable C, Wolfson J, Boro K, Rao R. Prevalence of anemia in pregnant women and its effect on neonatal outcomes in Northeast India. J Matern Fetal Neonatal Med. 2014;27(9):887-891. doi:10.3109/14767 058.2013.845161

9. Manju Merina Bara, Manjula Srivastava, Annie Samuel. Prevalence of anemia in pregnancy: A retrospective study at Tertiary care hospital in Jharkhand, India IOSR J Dent Med Sci. 2018;17(4): 25-28.

10. Rajamouli J, Ravinder A, SCK Reddy, Sujatha Pambi. Prevalence of anemia among pregnant women. Int J Contemp Res. 2016;3(8):2388-2391.

11. Haritha P, Lakshmi V, Veerraju P., Sarkar. B.N, Rao VR. Prevalence of Hemoglobinopathies among the Konda Kammaras of Visakhapatnam District, Andhra Pradesh. J Pharma Biol Sci .2012;2(4):6-8.

12. Kumar KJ, Asha N, Murthy DS, Sujatha MS, Manjunath VG. Maternal Anemia in Various Trimesters and its Effect on Newborn Weight and Maturity: An Observational Study.Int J Prev Med. 2013;4(2):193-199
13. Parks S, Hoffman MK, Goudar SS, Patel A, Saleem S, Ali SA et al. Maternal anemia and maternal, fetal, and neonatal outcomes in a prospective cohort study in India and Pakistan. BJOG. 2018;126(6). doi: 10.1111/ 1471-0528.15585.

14. Stephen G, Mgongo M, Hashim MH, Katanga J, Pedersen BS, Msuya SE,. Anemia in Pregnancy: Prevalence, Risk Factors, and Adverse Perinatal Outcomes in Northern Tanzania. Anemia 2018. https:// doi.org/10.1155/2018/1846280

15. Zhang Q, Ananth CV, Rhoads GG, Li Z. The impact of maternal anemia on perinatal mortality: a populationbased, prospective cohort study in China. Ann Epidemiol 2009; 19(11): 793-799. doi: 0.1016/j. annepidem. 2009.06.002.

16. Rahman MM, Abe SK, Rahman MS, Kanda M, Narita S, Bilano V, Ota E, Gilmour S, Shibuya K. Maternal anemia and risk of adverse birth and health outcomes in low- and middle-income countries: systematic review and meta-analysis. Am J Clin Nutrit 2016; 103: 495-504. doi: 10.3945/ajen.115.107896. Epub 2016 Jan 6.

17.Rani KU, Gupta J, Gupta R, Aggarwal KC. Maternal anemia and its severity: an independent risk factor for preterm delivery and adverse neonatal outcome. IJRCOG 2014;3(2):325-329. doi: 10.5455/ 2320- 1770. ijrcog20140607

\section{How to cite this article?}

Seetharama Raju K, Santhi Kothapalli, Gowri Shankar B. Prevalence of anemia in pregnant women and its impact on SNCU outcome. Int J Pediatr Res. 2019;6(08):411-417.doi:10.17511/ijpr. 2019.i08.04 